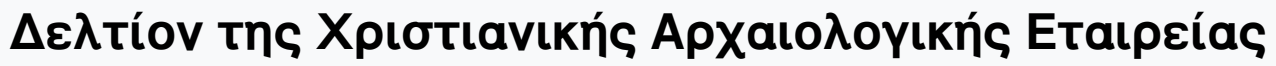

Tóp. 4 (1928)

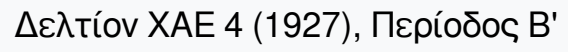

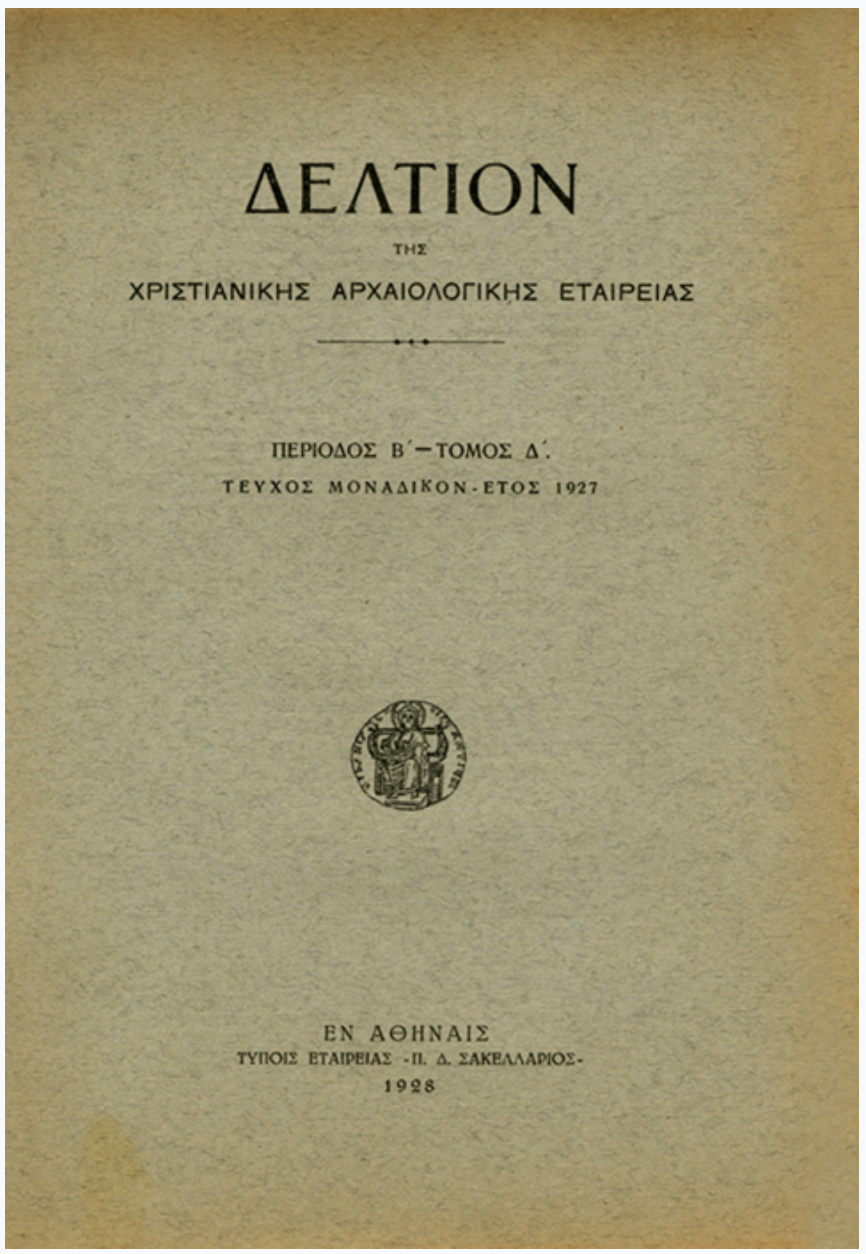

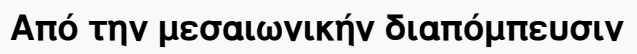

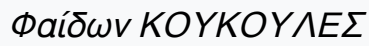

doi: $\underline{10.12681 / \text { dchae. } 1336}$

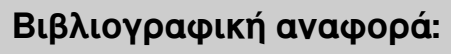

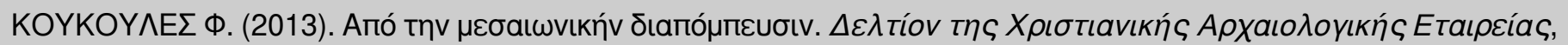
4, 62-66. https://doi.org/10.12681/dchae.1336 


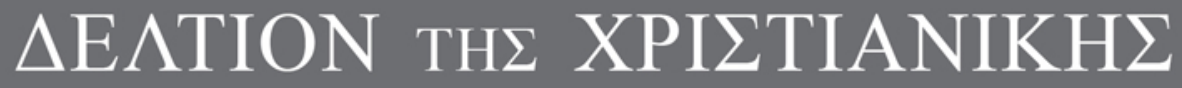 APXAIO $\Lambda$ OГIKH $\Sigma$ ETAIPEIA $\Sigma$}

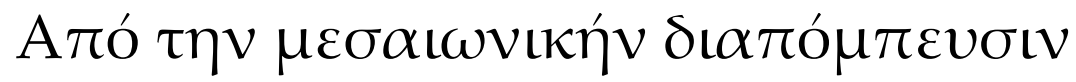

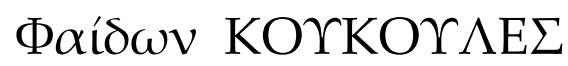

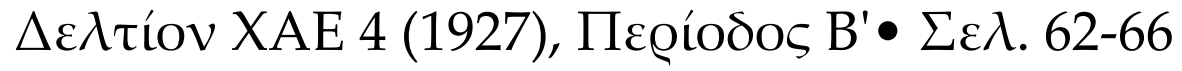

A@HNA 1928 


\section{AПO THN}

\section{ME $\Sigma$ AISNIKHN $\triangle \mathrm{IA \Pi OM \Pi EY \Sigma IN}$}

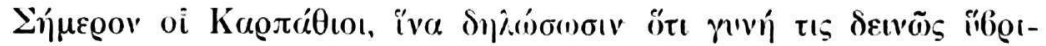

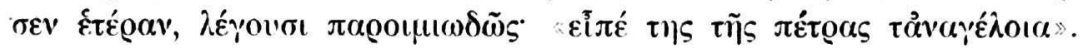

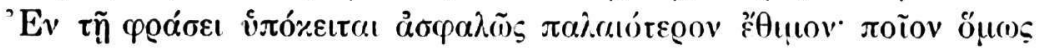

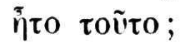

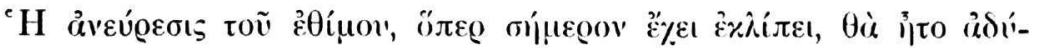

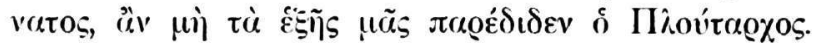

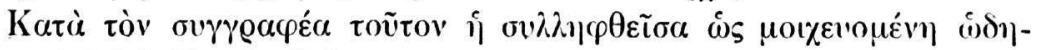

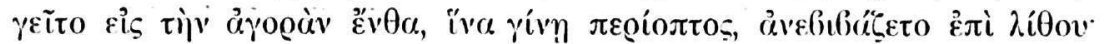

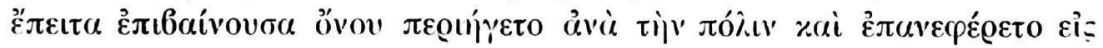

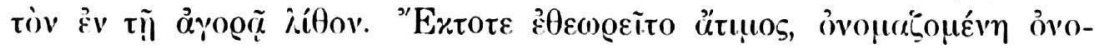
bútıc').

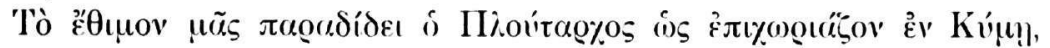
i vĩv ő

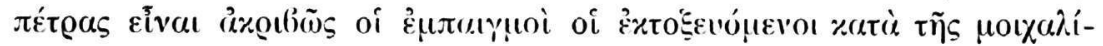

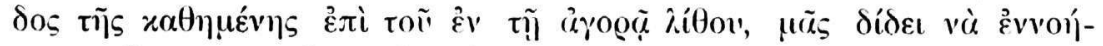

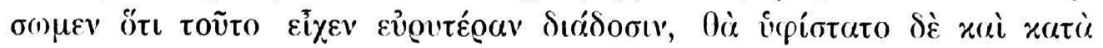

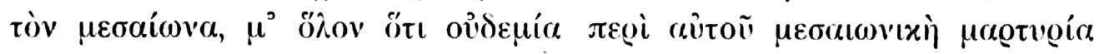

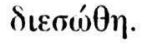

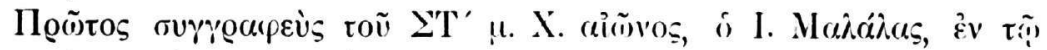

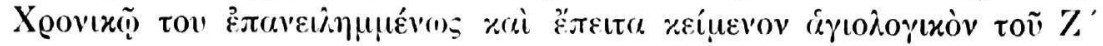

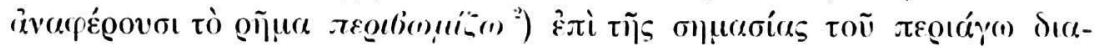

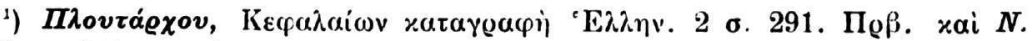

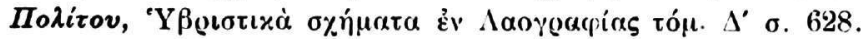

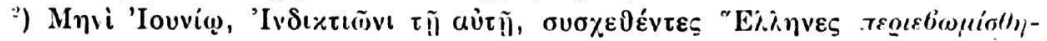

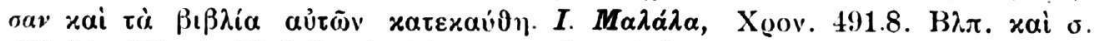

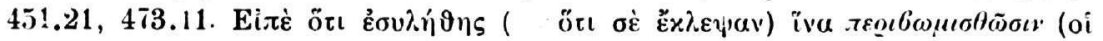

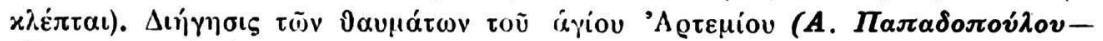

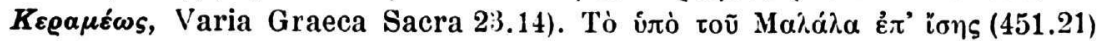

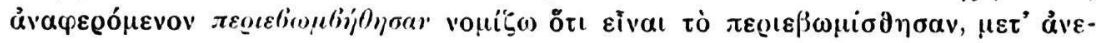

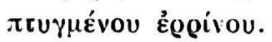




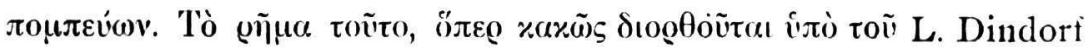

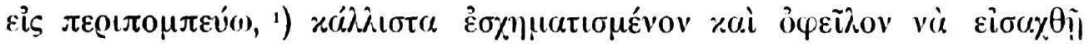

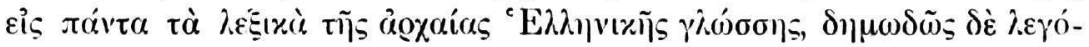

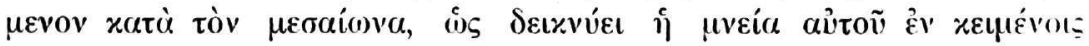

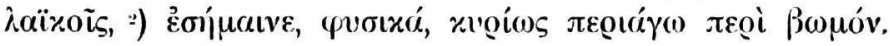

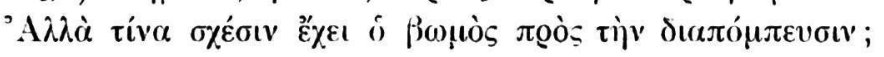

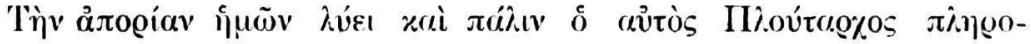

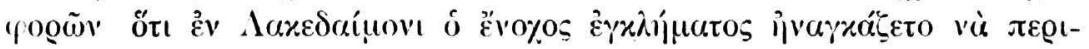

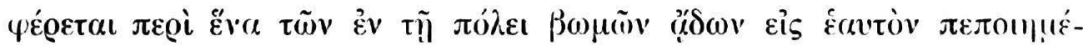
vov yórov").

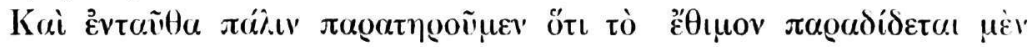

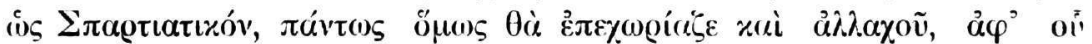

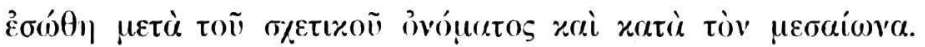

$B^{\prime}$.

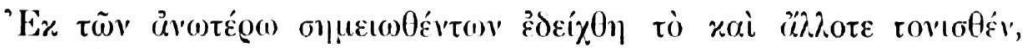

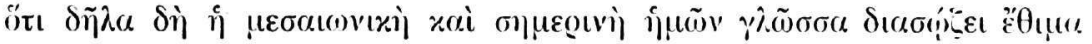

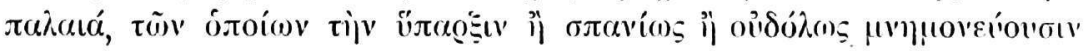

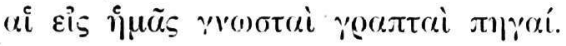

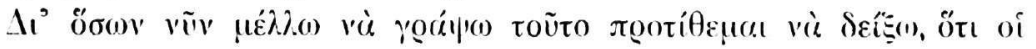

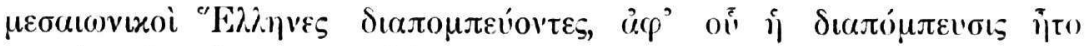

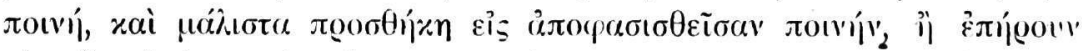

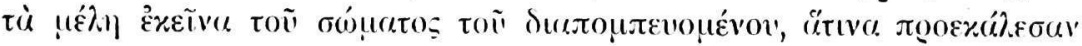

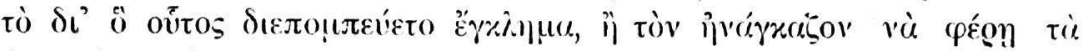

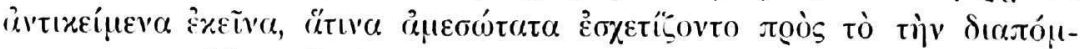

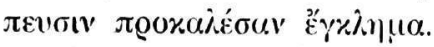

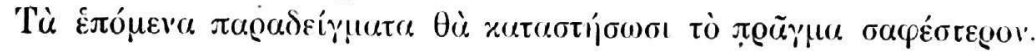

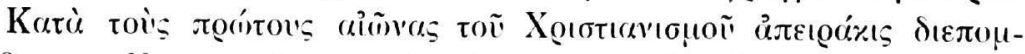

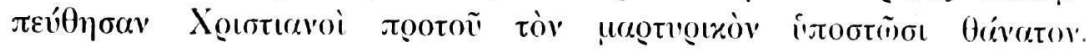

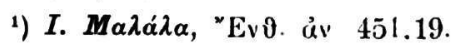

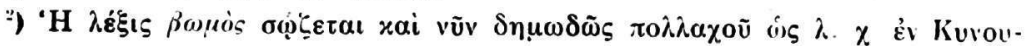

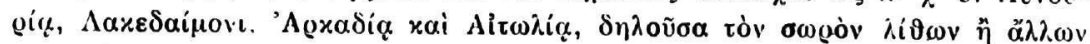

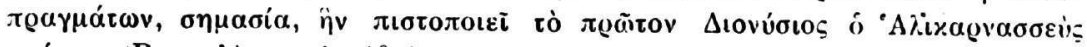

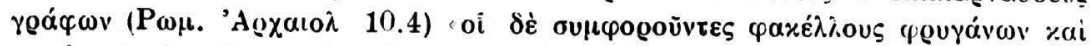

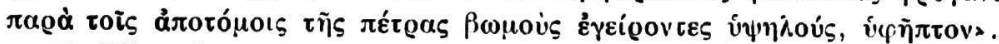

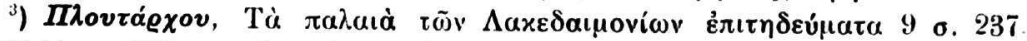

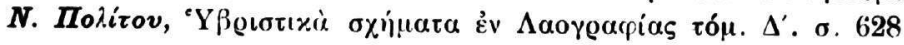




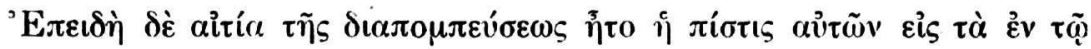

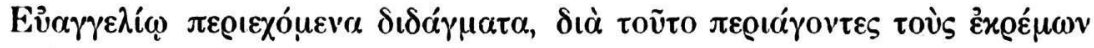

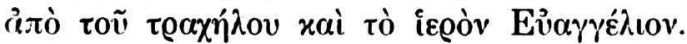

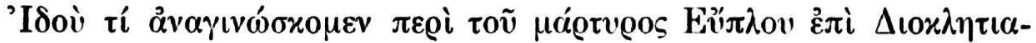

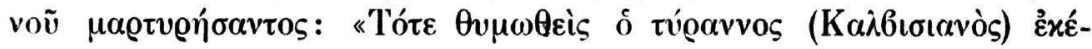

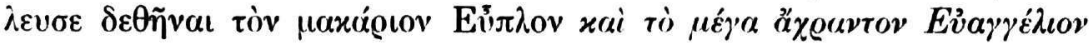

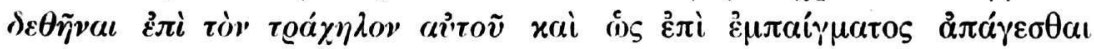

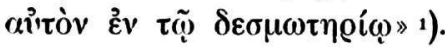

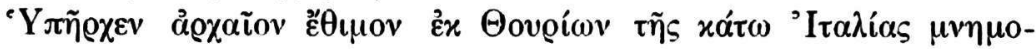
vevó $\mu \varepsilon v o v, x a \theta^{\prime}$ í of

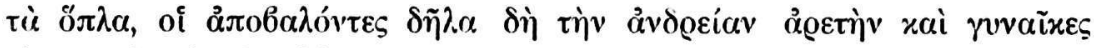

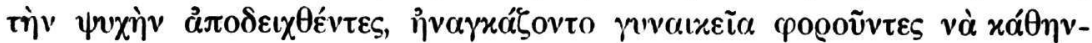

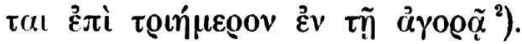

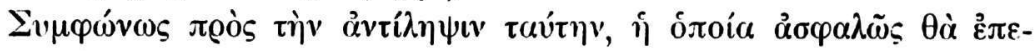

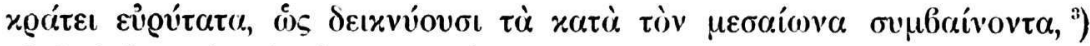

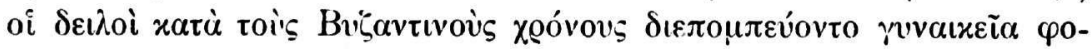

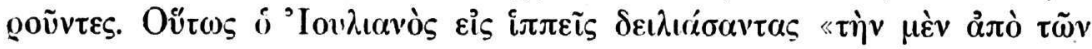

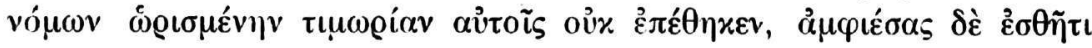

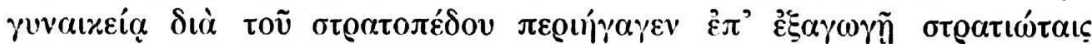

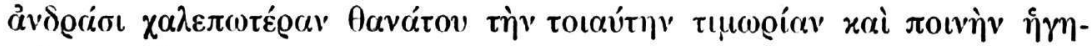

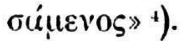

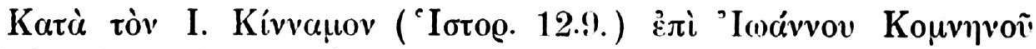

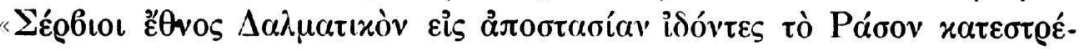

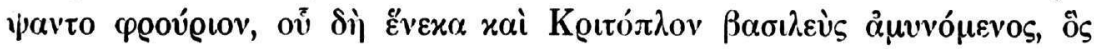

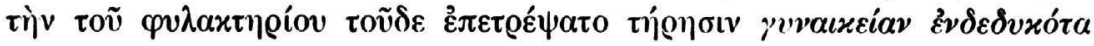

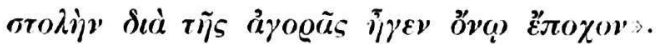

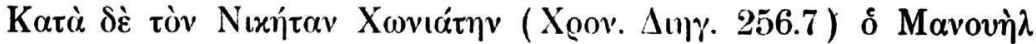

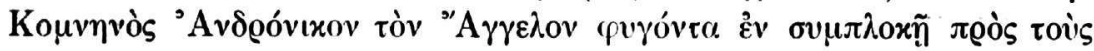

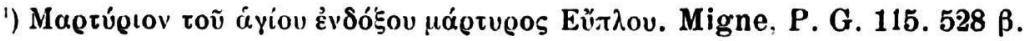

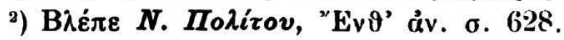

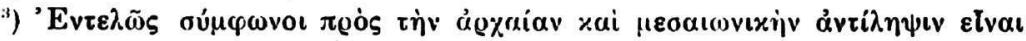

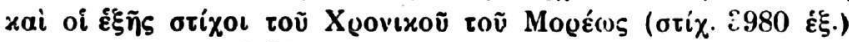

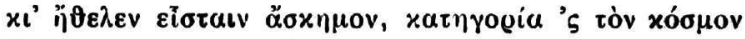

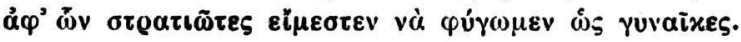

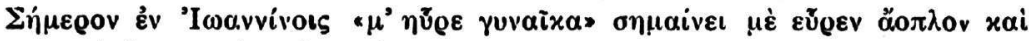

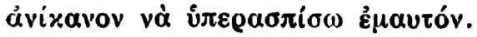

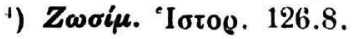




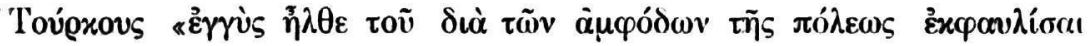

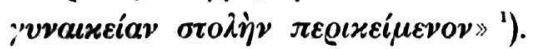

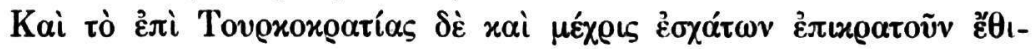

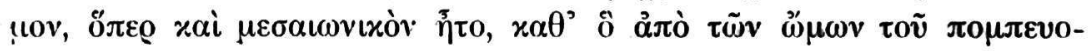

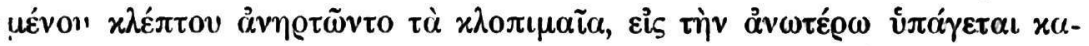

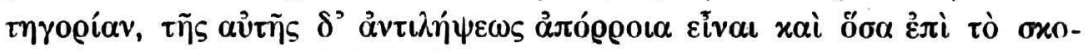

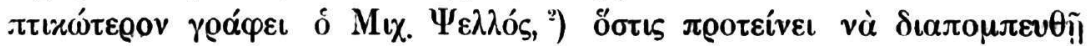

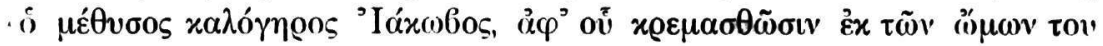
- ¿̀oxoì oívov.

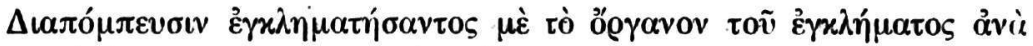

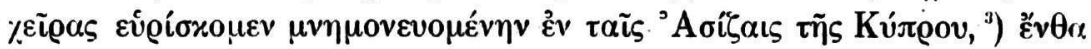

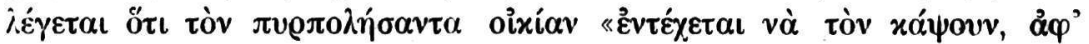

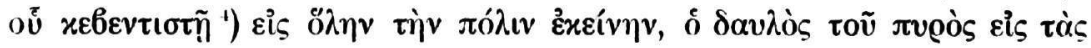
\%eīás rov».

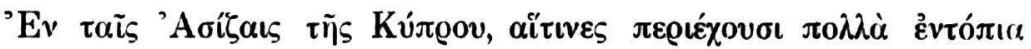

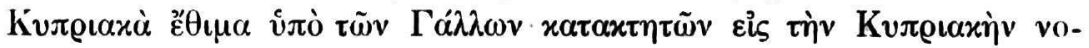

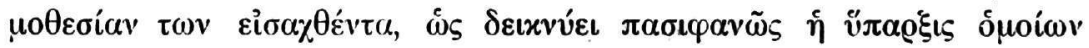

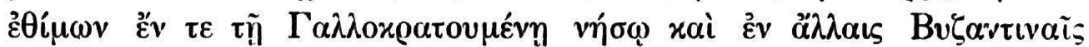

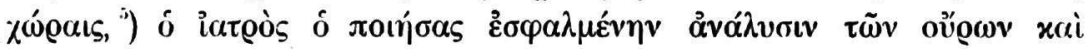

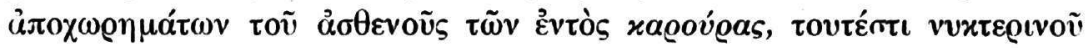

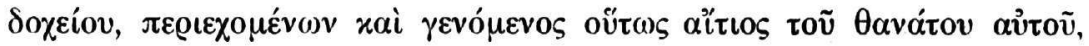

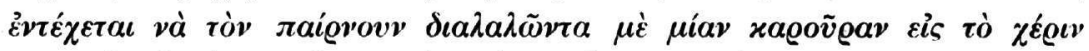

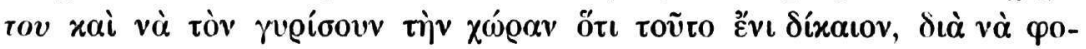
bęíoouv toùs étégous iat@oús").

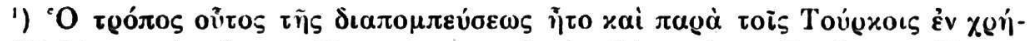

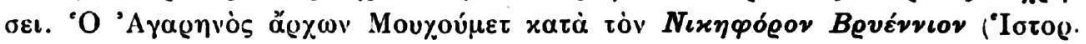

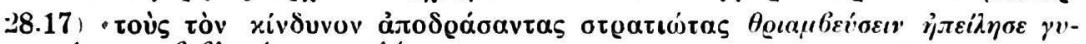

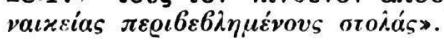

$\Rightarrow \mathrm{B} \lambda . K . \Sigma \alpha^{\prime} \theta \alpha, \mathrm{M \varepsilon \sigma} . \mathrm{B} \beta \lambda .5 .181$.

') А. $\sigma \xi \zeta^{\prime}, K . \Sigma \alpha \dot{\theta} \theta \alpha, \mathrm{M \varepsilon \sigma .} \beta \iota \beta \lambda .6 .223 .6$

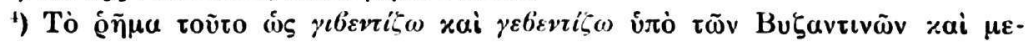

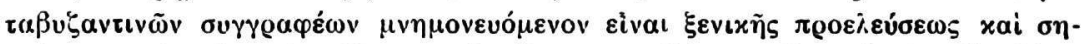

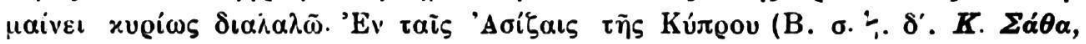

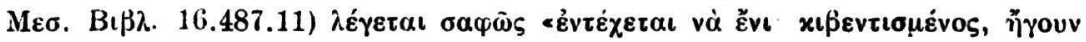

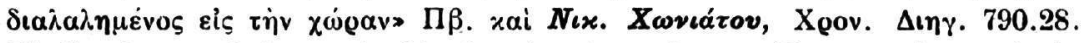

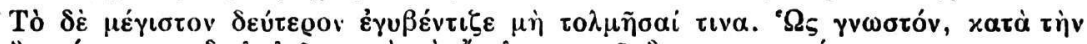

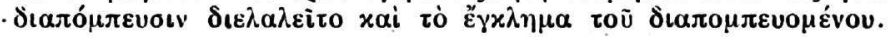

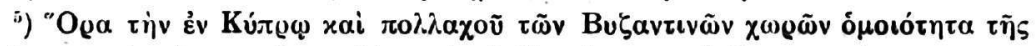

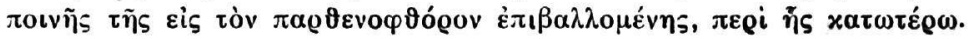

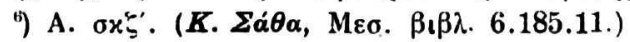




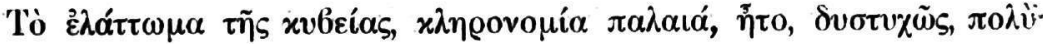

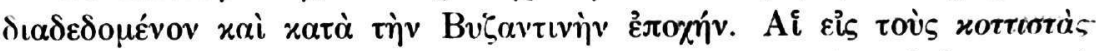

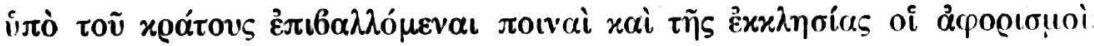

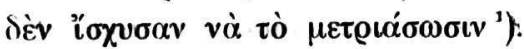

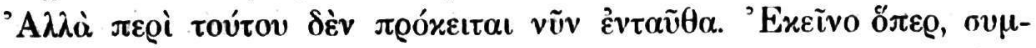
ц

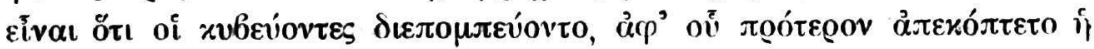

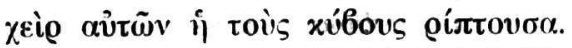

'I

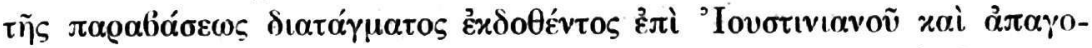

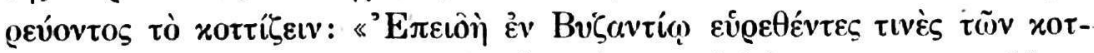

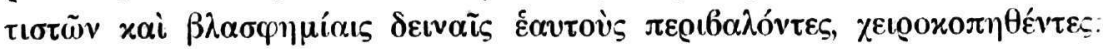

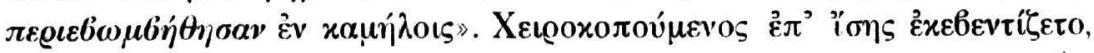

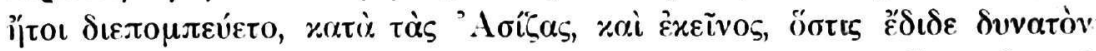

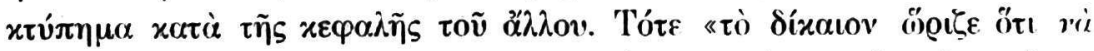

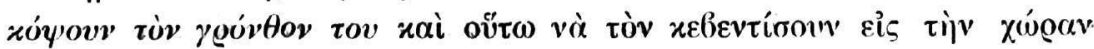

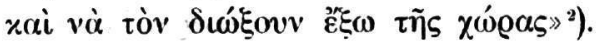

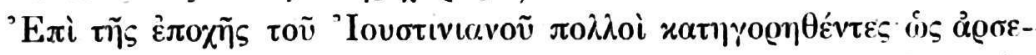

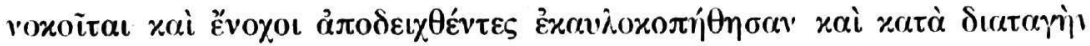

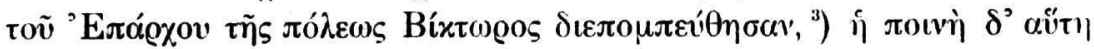

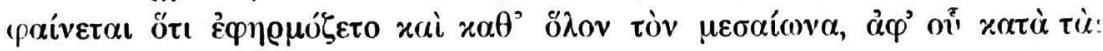

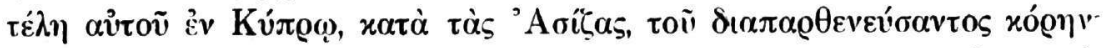

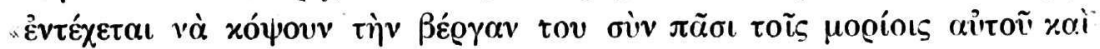

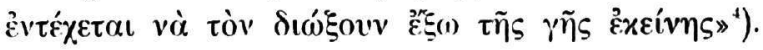

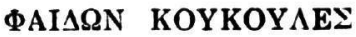

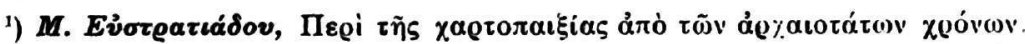

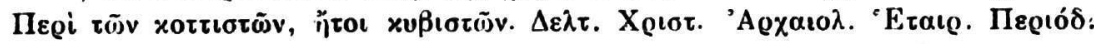
B'. тó $\mu$. Г'. б. $3 \ddot{\varepsilon} \xi$.

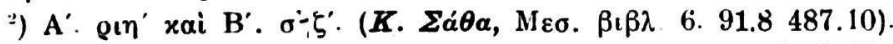

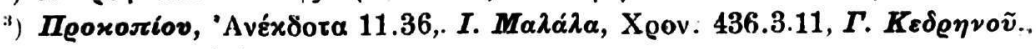

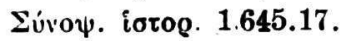

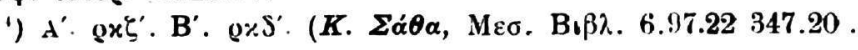

